\title{
Medical artificial intelligent research: translating artificial intelligence into clinical practice
}

The deep learning revolution and subsequent surge in the development of artificial intelligence (AI) didn't take long to reach the world of medicine. In this special series on "Medical Artificial Intelligent Research", we explore the latest developments through a collection of editorials, original articles, and reviews that set the stage for the challenges and opportunities in translating AI and related technologies into clinical practice. Medical AI is a rapidly developing field, and as technology advances it may offer the possibility to prevent, screen, diagnose, and treat patients in far-reaching corners of the developing world where skilled doctors and well-equipped hospitals are scarce. While the prospects are exciting, clinical application remains limited. This special series is an opportunity to take stock of the field and layout a roadmap for future development.

The contributions in this series come from physicians and academic researchers at the frontier of health care and AI research around the world. The interdisciplinary, boundary spanning nature of AI is evident throughout the works in this series, covering different fields of medicine, including dermatology, neurology, radiology, and ophthalmology. In addition to $\mathrm{AI}$, technologies with the potential to revolutionize medicine, such as blockchain and brain-computer interface, were also explored.

It should be noted that the variety of topics in this series are not only representative of the broad potential application of AI in medical specialties, but also demonstrative of the opportunity of AI application in all facets of medicine. From educating young doctors in the classroom, to the application of AI in lab research for quality control, as well as screening, diagnosing, and treating patients in the clinic-the broad potential of AI in medicine is elucidated by the contributions in this focused series.

With that in mind, several challenges remain for medical AI research to move forward. First, because the prospective application of $\mathrm{AI}$ in medicine is so broad, concerted effort must be made to move beyond research and drive research towards real world application. Ophthalmology shows great promise in this area, with applications such as CC-Cruiser and Visionome moving closer to real world deployment. Further, despite there being large amounts of medical data available for AI research, concerns such as privacy, data protection, ethics, and accountability must be addressed before the promise is fulfilled. Lastly, it is important to remember that despite all of the transformative potential offered by AI, the human relationship between doctors and patients remains to be the essence of medicine to be, something that must not get lost in AI revolution

This special series would not be possible without the tireless effort of the experts who contributed their knowledge. We hope that it serves as a step stone to future discoveries.

\section{Acknowledgments}

Funding: None.

\section{Footnote}

Provenance and Peer Review: This article was commissioned by the editorial office, Annals of Translational Medicine for the series "Medical Artificial Intelligent Research". The article did not undergo external peer review.

Conflicts of Interest: Both authors have completed the ICMJE uniform disclosure form. (available at http://dx.doi.org/10.21037/ atm-2020-mair-21). The series "Medical Artificial Intelligent Research" was commissioned by the editorial office without any funding or sponsorship. HL and LY served as the unpaid Guest Editors of the series. The authors have no other conflicts of interest to declare.

Ethical Statement: The authors are accountable for all aspects of the work in ensuring that questions related to the accuracy or integrity of any part of the work are appropriately investigated and resolved. 
Open Access Statement: This is an Open Access article distributed in accordance with the Creative Commons Attribution-NonCommercialNoDerivs 4.0 International License (CC BY-NC-ND 4.0), which permits the non-commercial replication and distribution of the article with the strict proviso that no changes or edits are made and the original work is properly cited (including links to both the formal publication through the relevant DOI and the license). See: https://creativecommons.org/licenses/by-nc-nd/4.0/.

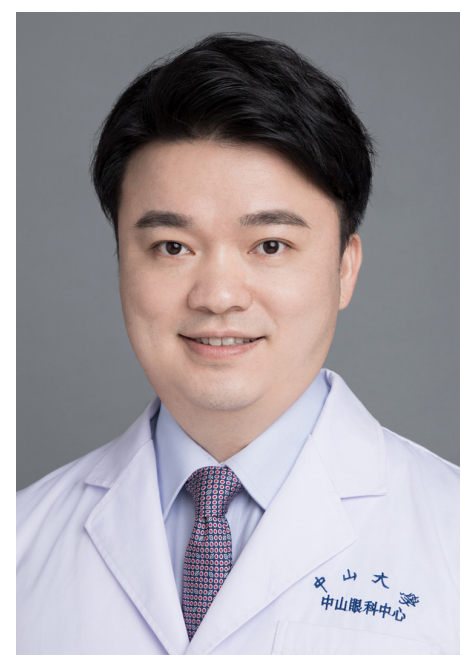

Haotian Lin

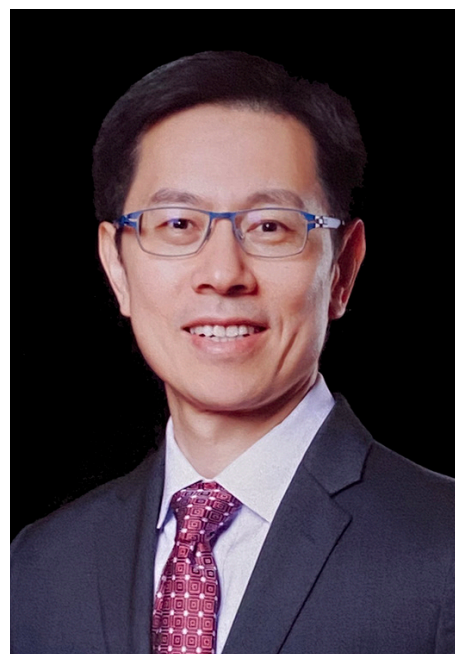

Limin $\mathrm{Yu}$

Haotian $\operatorname{Lin}^{1,2}$

${ }^{1}$ State Key Laboratory of Ophthalmology, Zhongshan Ophthalmic Center, Sun Yat-sen University, Guangzhou 510060, China; ${ }^{2}$ Centre for Precision Medicine, Sun Yat-sen University, Guangzhou, China.

(Email: gddlbt@aliyun.com)

Limin $\mathbf{Y u}^{3,4}$

${ }^{3}$ Department of Pathology, Beaumont Health, Royal Oak, MI, USA ${ }^{4}$ Oakland University, Rochester Hills, MI, USA.

(Email: limin.yu@beaumont.edu)

Submitted May 22, 2020. Accepted for publication Jun 10, 2020.

doi: 10.21037/atm-2020-mair-21

View this article at: http://dx.doi.org/10.21037/atm-2020-mair-21

Cite this article as: Lin H, Yu L. Medical artificial intelligent research: translating artificial intelligence into clinical practice. Ann Transl Med 2020;8(11):695. doi: 10.21037/atm-2020mair-21 